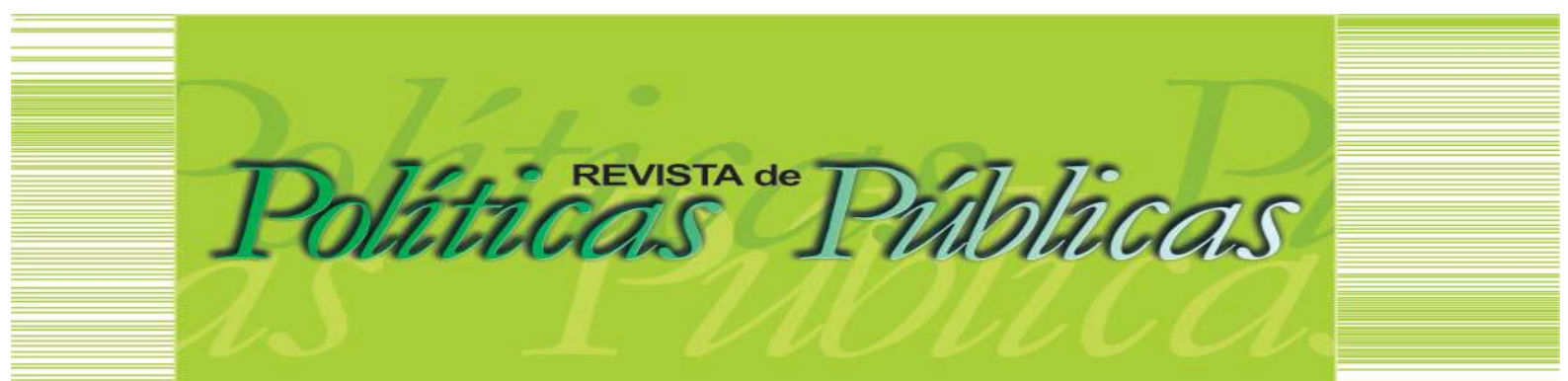

\title{
OS DESAFIOS NA ESCOLARIZAÇÃO DE ADOLESCENTES EM CUMPRIMENTO DE MEDIDA SOCIOEDUCATIVA DE LIBERDADE ASSISTIDA
}

\author{
Juscislayne Bianca Tavares de Morais ${ }^{1}$ \\ Maria D'alva Macedo Ferreira²
}

\begin{abstract}
Resumo
Este estudo qualitativo e bibliográfico versa sobre a escolarização dos adolescentes em cumprimento de medida socioeducativa de Liberdade Assistida (LA). A referida medida existe desde os Códigos Menoristas e sua operacionalização está diretamente relacionada à presença do adolescente no ambiente escolar e se na vigência da concepção Menorista, a LA objetivou a vigilância, com a promulgação do ECA ela passa a estar diretamente relacionada com o acompanhamento do adolescente a partir da Doutrina de Proteção Integral. Todavia, os estudos mostram que a relação escola e LA tem sido marcada por contradições, iniciando-se pela dificuldade destes adolescentes efetivarem a frequência escolar. Outro desafio é a não permanência na escola associada a condições multifatoriais, onde o que mais se sobrepõe é o não investimento dos governos na socioeducação. A universalidade do ensino e a permanência escolar são os dois maiores desafios da escolarização dos adolescentes em LA, que serão discutidos neste constructo teórico, com o intuito de desvelar a função da escola em interface com a socioeducação.
\end{abstract}

Palavras-chave: Escola. Socioeducação. Liberdade Assistida.

\section{THE CHALLENGES IN THE SCHOOLING OF ADOLESCENTS IN COMPLIANCE WITH THE SOCIO-EDUCATIONAL MEASURE OF ASSISTED FREEDOM}

\begin{abstract}
This qualitative and bibliographical study deals with the schooling of adolescents in compliance with the socioeducative measure of Assisted Living (LA). This measure exists since the Menorista Codes and its operationalization is directly related to the presence of the adolescent in the school environment. If, during the period of the Menorista conception, LA aimed at surveillance, with the promulgation of the ECA, it is directly related to the adolescent's follow-up from the Integral Protection Doctrine. However, studies show that the relationship between school and LA has been marked by contradictions, beginning with the difficulty of these young people to effect school attendance. Another challenge is not to remain in school associated with multifactorial conditions, where the most overlapping is the non-investment of governments in socioeducation. The universality of teaching and school permanence are the two major challenges of socioeducation that will be discussed in this theoretical construct, in order to unveil the role that the school has been playing in the face of Assisted Freedom.
\end{abstract}

Keywords: School. Socioeducation. Assisted Freedom.

Artigo recebido em: 22/04/2019 Aprovado em: 12/10/2019 DOI: http://dx.doi.org/10.18764/2178-2865.v23n2p621-639.

\footnotetext{
1 Psicóloga. Mestra em Políticas Públicas pela Universidade Federal do Piauí. Docente UNINTA e Psicóloga clínica na abordagem centrada na pessoa. E-mail: jusmoraiss@gmail.com

2 Assistente Social. Doutora em Serviço Social pela Pontifícia Universidade Católica de São Paulo (2003). Mestra em Serviço Social pela Pontifícia Universidade Católica de São Paulo (1997). Professora adjunta IV da Universidade Federal do Piauí. E-mail: mdalvaferreira@uol.com.br
} 


\section{INTRODUÇÃO}

A trajetória escolar dos adolescentes brasileiros, principalmente daqueles que cumprem medidas socioeducativas de Liberdade Assistida ${ }^{1}$ (LA), tem sido marcada por descontinuidades nos processos educativos. Por lei, crianças e adolescentes têm seu direito à escolarização respaldado juridicamente pela via de documentos legais, como: a Constituição Federal de 1988 (BRASIL, 1988), o Estatuto da Criança e do Adolescente (BRASIL, 1990) e a Lei de Diretrizes e Bases da Educação (BRASIL, 1996), todavia, as pesquisas mostram que os adolescentes em LA têm frequentemente seu direito à educação violado (CASTRO, 2016; PAVEZI, 2013; PIAZZAROLO, 2015; REHDER, 2017; SIQUEIRA, 2016; SOARES, 2017).

Os dados encontrados nos Levantamentos Anuais Socioeducativos sinalizam os altos índices de evasão escolar e distorção idade/ série na trajetória educacional de adolescentes que cumprem medidas socioeducativas em Meio Aberto (BRASIL, 2017; BRASIL, 2018). Nota-se, a partir das informações contidas nestes documentos, que existem poucas publicações de natureza quantitativas e qualitativas referentes ao acompanhamento da inclusão e permanência escolar, quando realizada em interface com a Liberdade Assistida.

Informações coletadas através do censo do Sistema Único da Assistência Social, referente ao ano de 2017, apontam que, 2577 Centros de Referência Especializada da Assistência Social (CREAS), localizados no Brasil, acompanham 19.873 adolescentes em cumprimento de Liberdade Assistida (MDS, 2018). Desse quantitativo, verificou-se que apenas 1850 adolescentes foram efetivamente encaminhados para a escola. Nesse contexto, questiona-se: como está sendo realizado o acesso à escolarização dos outros 10 mil adolescentes, cujos dados da trajetória escolar não têm sido considerados?

Diante do exposto, o referido artigo pretende problematizar a relação escola e Liberdade Assistida, em sua totalidade, considerando as contradições na efetivação da Doutrina de Proteção Integral e da perspectiva pedagógica no cenário socioeducativo. Esse artigo aborda os desafios na escolarização de adolescentes em LA considerando os seguintes tópicos: o primeiro item versa sobre "As raízes sócio- históricas e pedagógicas das medidas socioeducativas". Entender essas origens da socioeducação permite a compreensão do papel da escola diante das mudanças nas legislações voltadas à infância e adolescência no Brasil. Dessa forma, essa discussão será realizada centrada nos seguintes autores: Adorno, Bordini e Lima (1999), Carvalho (2002), Silva (2005), Faleiros (2005), Marinho e Galinkin (2017), Ortegal (2014), Perez e Passone (2010) e Rizzini e Rizzini (2004).

No segundo tópico, serão discutidos os "Desafios na interface Educação e Socioeducação no Contexto da Liberdade Assistida" a partir de teses e dissertações de Andrade 


\section{OS DESAFIOS NA ESCOLARIZAÇÃO DE ADOLESCENTES EM CUMPRIMENTO DE MEDIDA SOCIOEDUCATIVA DE LIBERDADE ASSISTIDA}

(2016), Ávila (2016), Castro (2016), Caparrós (2013), Collado (2013), Costa (2013), Lourenção (2015), Paula (2011), Pavezi (2013), Piazzarollo (2015), Rocha (2014), Siqueira (2016).

Ao longo do artigo também é realizado um recorte sócio- histórico e pedagógico da relação escola e LA através de documentos como: O Código de Menores de Mello de Mattos, Doutrina de Situação Irregular, Estatuto da Criança e do Adolescente, Levantamento Anual Socioeducativo, Censo SUAS e Diretrizes do SINASE.

\section{RAÍZES SÓCIO-HISTÓRICAS E PEDAGÓGICAS DA SOCIOEDUCAÇÃO NO BRASIL}

Abordar os desafios na escolarização de adolescentes em cumprimento de Liberdade Assistida, implica discorrer sobre os desdobramentos da relação escola e contexto socioeducativo. Afinal, como a escola foi introduzida enquanto espaço de socialização para aqueles que infringem as normas sociais? Qual o papel que tem sido desempenhado pela escola no âmbito socioeducativo?

Inicialmente é importante pontuar que crianças e adolescentes nem sempre foram reconhecidas enquanto sujeitos de direitos na realidade brasileira. A primeira legislação voltada à infância no Brasil foi promulgada em um período marcado pela precariedade no exercício dos direitos civis, políticos e sociais. Neste contexto, entre os anos de 1891 a 1930 o ideal liberal era forte e ao Estado não cabia a assistência social à população. A cidadania brasileira era uma cidadania negativa (CARVALHO, 2002).

O cenário supracitado se modifica quando entra em cena a ascensão do capitalismo no mundo que, inevitavelmente, repercutiu em mudanças sociopolíticas e culturais no Brasil. Zanela e Lara (2013) afirmam que as consequências do crescimento acelerado do país, acrescidas das mudanças na economia e nas legislações referentes a Justiça Juvenil nos Estados Unidos, Europa e América Latina, acabam por colaborar para a elaboração da primeira lei voltada ao atendimento dos intitulados menores no país, o Código de Menores de Melo de Mattos. Inclui-se nesse contexto a ascensão do modelo europeu de "Proteção Social" ou "Bem-Estar Social" do Welfare State (SILVA, 2005).

O Decreto de $n^{\circ}$ 17. 943, de 12 de outubro de 1927, que promulga o Código Melo de Mattos, consolidou as leis de assistência e proteção aos "menores"2 apresentando em seu artigo primeiro, enquanto principal finalidade, mostrar à população que caberia ao Estado 0 acompanhamento de crianças e adolescentes de ambos os sexos, abandonados ou delinquentes ${ }^{3}$ que fossem menores de 18 anos.

No período de promulgação do referido Código de Menores, o país passava por intensa industrialização e mudanças na economia, o que repercutiu diretamente no aumento da pobreza e violência enquanto expressões da questão social. Junto a esses novos fenômenos, também crescia o 
ideal do progresso, fazendo com que o Estado voltasse suas ações para aquelas pessoas às margens da escala produtiva, consideradas pelos governantes enquanto "potenciais causadores da desordem". É nesse ponto que as condições de vida das crianças abandonadas e consideradas delinquentes passam a ser consideradas um problema de higiene pública (FALEIROS, 2005, p. 172).

Nessa ordem liberal oligárquica reinante, aceitava-se uma intervenção mínima do Estado diante do problema da chamada infância desvalida, nos moldes do paternalismo, do autoritarismo e de reprodução da condição operária. 0 conceito- chave que foi consolidando ao longo do século XX na formulação de direitos e políticas no âmbito da infância foi o de situação Irregular.

Marinho e Galinkin (2017) mencionam que durante a vigência do Código de Menores o segmento infanto-juvenil era considerado potencialmente perigoso e isso fez com que o Estado não só agisse paternalmente, mas interviesse na vida privada das famílias brasileiras. O governo começa a intervir diretamente nas relações familiares e dita as normas do que seria o modelo ideal de acompanhamento às crianças e adolescentes em meio ao discurso higienista crescente que se referia aos "abandonados", "vadios", "vagabundos", enquanto sujeitos que deveriam ser recuperados.

No que se refere ao Código de Menores de Melo de Mattos, é possível observar a clara implementação de práticas de natureza repressiva e higienista aplicadas conforme as faixas etárias das crianças e adolescentes, considerando duas situações: o abandono e a delinquência. Dessa forma, a perspectiva educacional a ser aplicada por esse Código Menorista é materializada através dos chamados "Asylos Casa de Educação", "Escolas de Preservação" e "Escolas de Reforma".

No que se refere às medidas voltadas aos que infringem as normas sociais, é inaugurada a Liberdade Vigiada. Essa sanção educativa preconizou que o "menor"4 permaneceria sob a responsabilidade dos pais e tutores, sendo sua trajetória educacional acompanhada por um juiz. Este deveria comparecer em juízo nos dias da semana pactuados. Aos adolescentes com idade inferior aos 14 anos, o encaminhamento ocorria para as chamadas Escolas de Conservação; aos que tinham entre 14 e 18 anos, o mesmo ocorria para as Escolas de Reforma.

Conforme Marinho e Galinkin (2017), essa demanda de escolarização de crianças e adolescentes pobres surge devido ao cenário de abolição gradativa da escravidão, que fez com que surgisse a necessidade dessa mão de obra precoce. Nisto, criam-se os abrigos, os asilos e as escolas industriais e agrícolas onde as relações sociais eram diligenciadas pela lei.

No que se refere especificamente às Escolas de Reforma, o Código de 1927 aponta que sua finalidade era encaminhar o adolescente à educação para trabalho. Estas eram compostas por um corpo técnico formado por: 1 diretor, 1 escriturário, 1 amanuense, 1 almoxarife, 1 médico, 1 farmacêutico, 1 dentista, 1 instrutor militar, 4 professores primários, 4 mestres de oficinas, 1 mestre de desenho, 1 mestre de música, 1 mestre em ginastica, 1 inspetor geral e 4 inspetores. Para cada turma, 


\section{OS DESAFIOS NA ESCOLARIZAÇÃO DE ADOLESCENTES EM CUMPRIMENTO DE MEDIDA SOCIOEDUCATIVA DE LIBERDADE ASSISTIDA}

havia: 1 professor, responsável por trabalhar a educação individual dos adolescentes, e, segundo o artigo 20 do referido Código, o papel do professor era incutir nos adolescentes princípios morais, virtudes, trabalhar os deveres junto à família, à escola, à sociedade. A educação era voltada para aprendizagem da arte e 1 ofício (BRASIL, 1927).

No capítulo IV do Código de Menores de Mello de Mattos, expõe-se ainda a existência de institutos disciplinares voltados exclusivamente para meninas, sendo que nestes a escola deveria fornecer educação física, moral profissional ao segmento etário entre 7 e 18 anos de idade. A escolarização ocorria em pavilhões que conseguiam abrigar até três turmas de educandas com no máximo 20 alunas. Nessas instituições, as adolescentes eram rigorosamente observadas desde a sua entrada até sua permanência, podendo realizar os seguintes ofícios: costura, lavagem de roupa, datilografia entre outros. Já as jovens, entre os 14 e 18 anos, que cometiam infrações, eram encaminhadas às escolas de reforma, a chamada Escola Quinze de novembro5, onde eram internadas a partir de três turmas com no máximo 20 adolescentes.

Esse movimento de encaminhamento de crianças e adolescentes, para espaços de disciplinamento com foco na educação para o trabalho, faz parte do que Rizzini e Rizzini (2004), chamam de movimento de institucionalização das crianças no Brasil. Silva (2005) também nomeou essa onda de criação de instituições de "Movimento dos Reformadores", que ocupou destaque por protagonizar uma forte pressão para que ocorresse a separação dos chamados "menores" dos adultos".

Conforme o relatado anteriormente, as mudanças no trato à infância e adolescência no Brasil ocorrem devido às inúmeras expressões sociais emergentes da ascensão do capitalismo no país, mas também se acrescenta o fato de que a nova república buscava um novo ideal de homem e sociedade. Assim, Silva (2005, p.58) relata que "a solução encontrada foi a formalização de um "direito de menor" especializado com pilares humanitários e protecionistas", afinal "não ficava bem que as crianças respondessem o mesmo regime do Código Penal dos adultos" (SILVA, 2005, p. 58).

Nesse ínterim, é instaurada, na década de 1940, uma instituição exclusivamente voltada ao acompanhamento de adolescentes, no caso, o Serviço de Assistência aos Menores (SAM). Essa instituição foi alvo de inúmeras críticas, pois o sucesso de sua proposta educacional era depositado diretamente nos assistidos pelo serviço, que quando não cumpriam as expectativas eram considerados: "incapazes", "subnormais" e "subnormais de inteligência e afetividade (RIZZINI.; RIZZINI, 2004).

É a partir desse enfoque que nasce a terminologia "delinquente", utilizada preco nceituosamente para demarcar o comportamento infantil considerado problemático e entendido enquanto ameaça em potencial. Os estabelecimentos ligados ao SAM, como 
patronatos, as Colônias Agrícolas e os Centros de Recuperação, tinham estrutura e funcionamento análogos aos do sistema penitenciário, tornando-se verdadeiras prisões, com diferentes tipos de violações de direitos e crueldades (SILVA, 2005, p. 63).

A SAM computava um total de 33 educandários localizados por todo país e em plena expansão, contando ainda com estabelecimentos particulares articulados. Sua perspectiva pedagógica era balizada na criminologia positivista europeia do século XIX, que atribuía causas biológicas e psicológicas para as condutas transgressoras, consideradas em si "patológicas" (SILVA, 2005). A referida instituição passou a ser alvo de denúncias por corrupção, uma vez que, os educandários particulares recebiam por adolescentes internado, mas não eram vinculados juridicamente ao órgão federal. Acrescenta-se ainda o fato de que a proposta pedagógica da SAM foi questionada, pois, passou a ser chamada pela mídia e a sociedade, enquanto escola, de transviados e escola do crime (RIZZINI.; RIZZINI, 2004). Na verdade, "o hiato entre o marco histórico dos direitos universais da criança e a realidade do atendimento existente no Brasil levou ao questionamento do SAM e do próprio Código de Menores" (PEREZ;; PASSONE, 2010, p. 668).

Dada a gravidade da situação de falência nas SAMs, o governo no ano de 1964 cria a Política Nacional do Bem-Estar ao Menor (PNBM) e a Fundação Nacional do Bem-Estar do Menor (FUNABEM), sendo a elas vinculadas as Fundações de Bem-Estar Social (FEBENS). A FUNABEM é criada sob a égide da chamada Escola Superior da Guerra, cujas linhas de delineamento de suas ações eram respaldadas na concepção harmônica de sociedade (SILVA, 2005). Considerando a falência do modelo da SAM, houve também a necessidade da criação de uma nova legislação voltada à infância e à adolescência, uma vez que o Código Melo de Mattos estava esgotado. Assim, a Doutrina de Situação Irregular é promulgada através da lei $n^{\circ}$ 6.697, de 10 de outubro de 1979.

A referida Doutrina de Situação Irregular é elaborada em uma fase de fortes debates em relação aos "direitos dos menores", influenciados pelo Fundo das Nações Unidas da Infância, Declaração Universal dos Direitos da Criança e Convenções Internacionais pelos Direitos da Infância. Na prática, o Brasil se comprometeu com as organizações internacionais para elaboração de um novo Código de Menores, contudo, a nova lei não modifica o trato higienista às questões da infância (PEREZ; PASSONE, 2010).

O Código de 1979 dispõe sobre a assistência, proteção e vigilância a menores até 18 anos de idade, que se encontram em Situação Irregular. Coube a essa nova legislação designar como o Estado deveria acompanhar crianças e adolescentes que passavam por omissão dos pais, aquelas cujos pais não poderiam the prover, vítimas de maus tratos, em situação de perigo real, as que se encontravam em ambiente que iriam contra os maus costumes, os que apresentavam grave inadaptação familiar e os autores de infração. 


\section{OS DESAFIOS NA ESCOLARIZAÇÃO DE ADOLESCENTES EM CUMPRIMENTO DE MEDIDA SOCIOEDUCATIVA DE LIBERDADE ASSISTIDA}

Já aos adolescentes autores de infração, o referido código direcionava a autoridade judiciária à aplicação das seguintes medidas: advertência, entrega aos pais, colocação em lar substituto, imposição de liberdade assistida, colocação em casa de semiliberdade e internação em estabelecimento educacional. Na aplicação dessas medidas, a escolarização e profissionalização se tornaram obrigatórias nos centros de permanência.

Apesar da tentativa do Estado brasileiro, em promover o êxito das Doutrinas Menoristas, aumentaram os questionamentos em relação à internação de crianças e adolescentes nos anos 1980 .

No final dos anos 1970 e início dos anos 1980, passam a ser perceptíveis as inquietações em relação à eficácia deste tipo de medida. É indicativo desse novo momento o grande número de seminários, publicações e discussões em torno de iniciativas que indicassem novos caminhos. A palavra de ordem na época era a busca de alternativas, subentendendose que se tratava de alternativas à internação (RIZZINI.; RIZZINI, 2004, p. 46).

O esgotamento da perspectiva Menorista ocorre em pleno cenário mundial de fortalecimento das políticas públicas voltadas às crianças e adolescentes, e demarcadas por duas tendências: a primeira tendência foi a criação das recomendações e normativas por parte dos organismos internacionais, entre as quais estavam: As Regras de Beijing, as Recomendações R20, os princípios de Ryadh para prevenção da violência juvenil e as Regras de Havana. Essas leis, recomendações e normativas internacionais surgiram entre as décadas de 1980 e 1990, e se dirigiram ao governo e à justiça especializada. A segunda tendência, que surge na década de 1980, recai na pressão da sociedade industrial para reverter as políticas liberais voltadas aos adolescentes em um cenário de ampliação do cometimento de atos infracionais no mundo. Surge a justiça especializada para jovens, preconizando os programas de apoio comunitário de caráter preventivo (ADORNO; BORDINI; LIMA, 1999).

O ECA foi uma conquista tardia na luta pelos direitos sociais à infância e à adolescência, $\mathrm{e}$ reflete a vitória dos movimentos sociais. Foi uma garantia legislativa elaborada em meio ao fortalecimento do neoliberalismo, ainda no Governo do Presidente Fernando Collor de Mello e tem, enquanto inovação, a criação do Sistema de Garantias de Direitos e a possibilidade da participação popular a partir da criação dos Conselhos Tutelares e Conselhos Municipais da Criança e do Adolescente. 0 Estatuto sistematiza os direitos das crianças e dos adolescentes, norteando a lei a partir das políticas sociais direcionadas a questões específicas (SILVA, 2005).

A conjuntura histórico-internacional de elaboração da referida legislação foi marcada pelas inúmeras mudanças que estavam sendo inseridas pelo surgimento da globalização, entre as quais estavam: as mudanças na relação capital $x$ trabalho, mudanças no padrão fordista de produção, avanço do sistema de acumulação flexível, reestruturação produtiva, desemprego, a juventude que contestava os padrões sociais da época a partir da insubordinação ao Estado. As consequências desse 
cenário foram o xenofobismo, intolerância zero, intensificação das migrações, aumento da pobreza, aparecimento das novas expressões da questão social (SILVA, 2005).

Em meio ao processo de redemocratização do país, ficou claro que as alternativas à internação limitavam as possibilidades de desenvolvimento de crianças e adolescentes. 0 órgão central de atendimento à infância, a FUNABEM, precisou passar por uma restruturação e ao final de 1980 se transforma em Centro Brasileiro para a Infância e Adolescência que tinha, enquanto missão principal, acompanhar e apoiar a implementação do Estatuto da Criança e do Adolescente- ECA (RIZZINI.; RIZZINI, 2004).

O ECA, promulgado no ano de 1990, passa a conceber crianças e adolescentes, enquanto sujeitos, alvos da Proteção Integral do estado e da sociedade. A nova lei culmina nas seguintes mudanças:

- Foco na centralidade da família;

- Criação do Sistema de Garantias de Direitos;

- Excepcionalidade da Internação;

- Não criminalização da situação de pobreza dos pais

- Mudanças no trato dos adolescentes autores de atos infracionais, sendo as crianças consideradas inimputáveis;

- Criação das medidas socioeducativas.

Verifica-se, a partir dos itens elencados, que houve significativas mudanças no que trata do acompanhamento das crianças e adolescentes em situação de abandono e que cometeram atos infracionais. Estes, que antes tinham suas trajetórias de vida criminalizadas, passam a ser considerados sujeitos de direitos. 0 discurso centrado nas perspectivas biologicista e psicologistas se modifica, e a violência/ abandono passam a ser considerados pelos atores das políticas públicas enquanto uma expressão da questão social.

No caso dos adolescentes que praticaram atos infracionais, verifica-se no corpo legislativo do ECA as mesmas prerrogativas de acompanhamento na Doutrina de Situação Irregular. Ao trazer as comparações abaixo é possível visualizar as continuidades e descontinuidades entre a antiga Doutrina de Situação Irregular comparada à Doutrina de Proteção Integral (SILVA, 2005).

O ECA conferiu aos adolescentes autores de atos infracionais direitos e deveres como, por exemplo: o devido processo legal; a ampla defesa; a presunção da inocência; a assistência jurídica; a garantia da presença dos pais e responsáveis nos procedimentos judiciários; o direito de ser informado das acusações e de não responder; de confrontação de testemunhas; de interposição de recursos; de apelação para autoridades em diferentes instâncias hierárquicas; o acompanhamento 


\section{OS DESAFIOS NA ESCOLARIZAÇÃO DE ADOLESCENTES EM CUMPRIMENTO DE MEDIDA SOCIOEDUCATIVA DE LIBERDADE ASSISTIDA}

intersetorial das políticas públicas; a responsabilização conforme a gravidade do delito; o direito ao habeas corpus, sendo vetado o encarceramento nas prisões (SILVA, 2010).

0 referido estatuto pontua que o acompanhamento dos delitos cometidos por adolescentes deverão ser realizados através das Medidas Socioeducativas. Ranieri (2014) menciona que, quando "inventadas as medidas socioeducativas", vê-se que as medidas de caráter predominantemente pedagógico seguem três caminhos: advertência, as medidas em meio aberto (Liberdade Assistida e Prestação de Serviço à Comunidade), a semiliberdade e à medida em meio fechado, excluindo, claro, as advertências que não implicaram encaminhamento ao cumprimento no contexto socioeducativo.

Nota-se, ainda, que o ECA continua a adotar a Liberdade Assistida enquanto caminho de responsabilização dos adolescentes.

Quadro 1 - Liberdade no ECA

\begin{tabular}{|c|c|c|}
\hline Liberdade Vigiada (Código de 1927) & $\begin{array}{l}\text { Liberdade Assistida (Código de } \\
\text { 1979) }\end{array}$ & Liberdade Assistida (ECA, 1990) \\
\hline $\begin{array}{c}\text { Art. 98- } \\
\text { A pessoa encarregada da vigilância } \\
\text { do menor é obrigada a vigiá-lo em sua } \\
\text { casa ou qualquer outro lugar. } \\
\text { Aplicada conforme a perversão e nível } \\
\text { moral do adolescente } \\
\text { As visitas deverão ser periódicas, cujo } \\
\text { relatório sobre a situação moral e } \\
\text { material deve ser encaminhada para o } \\
\text { juiz } \\
\text { Encaminhamento do adolescente aos } \\
\text { institutos de educação, escolas de } \\
\text { preservação. }\end{array}$ & Vigiar, punir, tratar e orientar o menor. & $\begin{array}{l}\text { Art. 118- A liberdade Assistida será } \\
\text { adotada sempre se configurar a mais } \\
\text { adequada para acompanhar, auxiliar e } \\
\text { orientar o adolescente } \\
\text { Acompanhamento por até seis meses, } \\
\text { condicionado à frequência escolar e à } \\
\text { presença de um orientador social. } \\
\text { Caberá ao juiz o acompanhamento da } \\
\text { medida via relatório }\end{array}$ \\
\hline
\end{tabular}

O quadro anterior exemplifica o que Silva (2005/2010) chama de continuidades e descontinuidades do ECA. Ou seja, observando-se a aplicação da Liberdade Assistida, verifica-se a existência de elementos e terminologias utilizadas na Doutrina Menorista e que ainda são aplicadas pela Doutrina de Proteção Integral. Contudo, é reconhecido que o ECA, apesar de lidar com inúmeros desafios na sua efetivação, é um modelo que tem o propósito claro de romper com as políticas públicas que criminalizam a pobreza. Por outro lado, o ponto mais difícil da legislação que tem sido constantemente questionado refere-se justamente às medidas socioeducativas.

Esse formato alternativo de responsabilização, em conformidade com a nova visão dos direitos infanto-juvenis advindos da Constituição Cidadã, e respectivo ECA, configura-se em uma sanção, todavia, diferenciada e de acordo com os princípios norteadores pré-estabelecidos. As diretrizes que versam sobre a forma como as medidas socioeducativas poderão ser implementadas é 
fornecida através da Política Nacional de Atendimento Socioeducativo elaborada no ano de 2006 e materializada através do Sistema Nacional Socioeducativo (SINASE).

O Sistema Nacional Socioeducativo (SINASE) foi elaborado sob forte influência das normativas nacionais e internacionais pelas quais o Brasil é regido, como: a Convenção da ONU sobre Direitos Humanos da Criança, Sistema Global, Sistema Interamericano dos Direitos Humanos: Regras Mínimas de Beijing-Regras Mínimas das Nações Unidas para Proteção de Jovens Privados de Liberdade (ORTEGAL, 2014). Trata-se de um conjunto de diretrizes voltadas a nortear o processo que abarca desde o momento que 0 ato infracional é apurado até a execução da medida socioeducativa (BRASIL, 2012).

O SINASE fortalece a prerrogativa pedagógica das medidas socioeducativas, considerando 11 eixos pedagógicos norteadores:1. Prevalência da ação socioeducativa sobre os aspectos meramente sancionatórios; 2. Projeto pedagógico como ordenador de ação e gestão do atendimento socioeducativo; 3. Participação dos adolescentes na construção, no monitoramento e na avaliação das ações socioeducativas; 4. Respeito à singularidade do adolescente, presença educativa e exemplaridade como condições necessárias na ação socioeducativa; 5. Exigência e compreensão, enquanto elementos primordiais de reconhecimento e respeito ao adolescente durante 0 atendimento socioeducativo; 6. Diretividade no processo socioeducativo; 7. Disciplina como meio para a realização da ação socioeducativa; 8 . Dinâmica institucional garantindo a horizontalidade na socialização das informações e dos saberes em equipe multiprofissional;9. Organização espacial e funcional das Unidades de atendimento socioeducativo que garantam possibilidades de desenvolvimento pessoal e social para o adolescente; 10. Diversidade étnico-racial, de gênero e de orientação sexual norteadora da prática pedagógica; 11. Família e comunidade participando ativamente da experiência socioeducativa (BRASIL, 2012).

Apesar da ampla quantidade de Diretrizes Pedagógicas, identifica-se que poucas publicações do governo federal versam sobre como aplicar na prática os princípios da socioeducação, elencando-se apenas as publicações de "Por uma Política Nacional de Execução das Medidas Socioeducativas: Conceitos e Princípios Norteadores", "As Bases Éticas da Ação Socioeducativa", "Os Regimes de Atendimento no Estatuto da Criança e do Adolescente", "Socioeducação - Estrutura e Funcionamento da Comunidade Educativa" e, por último, "Parâmetros para a formação do educador" elaborados por Antônio Carlos Gomes da Costa.

Diante do exposto, constatou-se que nas raízes da socioeducação brasileira encontra-se um modelo educacional voltado a conter a violência e outras expressões da questão social de forma simplista e repressiva. Não se nega a importância das primeiras legislações voltadas às crianças e adolescentes, afinal, elas foram as primeiras a garantir um atendimento diferenciado a esse segmento 


\section{OS DESAFIOS NA ESCOLARIZAÇÃO DE ADOLESCENTES EM CUMPRIMENTO DE MEDIDA SOCIOEDUCATIVA DE LIBERDADE ASSISTIDA}

educacional. Contudo, pouco se refletiu sobre o papel da educação neste cenário e pouco se discutiu a trajetória educacional dos adolescentes assistidos pelos Códigos Menoristas, sendo essa problematização efetivamente iniciada com a implementação do Sistema Nacional Socioeducativo.

\section{DESAFIOS NA INTERFACE EDUCAÇÃO E SOCIOEDUCAÇÃO NO CONTEXTO DA LIBERDADE ASSISTIDA}

Conforme o tópico anterior, que versa sobre as raízes da socioeducação, ou melhor, do que seria a chamada perspectiva pedagógica, observa-se que, enquanto a internação é considerada uma medida a ser evitada e aplicada em último caso, a Liberdade Assistida é a medida cuja aplicação é recomendada em Meio Aberto. Neste artigo entende-se a escolarização na medida socioeducativa associada a uma produção do conhecimento que ainda não superou o paradigma Menorista instaurado no século XX (PAULA, 2011). Nesse sentido, neste ponto da pesquisa é colocada a seguinte pergunta: Quais são os desafios na escolarização dos adolescentes em cumprimento de medida socioeducativa de Liberdade Assistida?

Inicia-se essa discussão pontuando que a escola é considerada um espaço amplo de socialização que busca favorecer experiências de produção de conhecimento para a vida e deve garantir o respeito à liberdade e à tolerância, todavia, quando é articulada ao cenário socioeducativo, seu significado passa a ser permeado de polêmicas (SIQUEIRA, 2016). Acerca da realidade escolar no âmbito socioeducativo, Caparrós (2013), em pesquisa realizada com adolescentes que cumprem medida socioeducativa de Liberdade Assistida na cidade de São Carlos-SP, expõe que a escola é importante espaço para formação da identidade dos adolescentes, cujas vivências, a priori, deveriam ser de pertencimento, contribuindo para a formação de consciência crítica, entretanto, o retorno à rotina escolar não parece simples, principalmente devido à ausência de vagas e ao preconceito.

Quando se pensa na relação escola e Liberdade Assistida, verifica-se que, na transição do Período Menorista para a Doutrina de Proteção Integral, a escola se coloca na primeira fase enquanto punição; já na segunda fase, enquanto Proteção. Todavia, diante do cenário de constante questionamento em relação à eficácia das medidas socioeducativas e da aplicação das perspectivas pedagógicas na socioeducação, tem sido crescente o questionamento em relação a como tem sido a relação escola e LA, uma vez que os dados mostram que essa interação não tem sido eficaz, quando não, inexistente.

Considerando o referido contexto, pontua-se que a realidade de descontinuidades no que tange ao acesso à educação ${ }^{6}$, também é encontrada no cenário socioeducativo. Neste âmbito, constataram-se, através das análises dos Censos Escolares da Educação Básica referentes aos anos 
2014, 2015 e 2017, informações incipientes acerca da escolarização dos adolescentes inseridos no Sistema Socioeducativo e nenhuma informação sobre a situação escolar de adolescentes em cumprimento de medida socioeducativa de Liberdade Assistida.

Apesar da quantidade insuficiente de dados que possam efetivamente fornecer um panorama geral da efetivação do direito à escolarização, pois, não há um recorte estatístico nacional da inclusão escolar no contexto socioeducativo nas realidades municipais e estaduais, ainda se tem teses e dissertações que mostram a realidade de contextos pontuais no eixo da escolarização das medidas socioeducativas de Liberdade Assistida, principalmente no que se refere à não garantia ao direito à educação. Essa carência de informações é explicada por Castro (2016, p. 56).

No Brasil há poucos estudos e debates sobre 0 aprendizado escolar de adolescentes infratores/as, pois há a injunção de que a partir do momento em que um/a adolescente cometeu um delito, não há mais volta, como se ele/a não pudesse se redimir de seus atos, retomar os estudos e ter uma vida digna. Cria-se um estigma social de que este/a adolescente será um/a 'criminoso/a' para o resto da vida.

Nesse sentido, Lourenção (2015), em pesquisa desenvolvida na cidade de Presidente Prudente- São Paulo, identificou a partir de dados coletados no CREAS que, dos 197 adolescentes que haviam cumprido medida socioeducativa de Liberdade Assistida, 137 não estudavam quando praticaram atos infracionais.

\footnotetext{
São números bastante representativos, pois evidenciam a evasão escolar presente na vida dos adolescentes, antes mesmo do cometimento do ato infracional. É também um dado instigador que nos leva a questionar que papel a escola vem desempenhando como instituição protetiva e inibidora de situações de risco. Também nos instiga a problematizar sobre eventuais lacunas nos serviços de proteção social básica e vigilância social (LOURENÇÃO, 2015, p. 99).
}

A pesquisa de Castro (2016, p. 36), realizada junto a 19 adolescentes que cumpriram medida socioeducativa de Liberdade Assistida na cidade de Palmas-TO, também mostrou que a maioria destes não frequentavam regularmente a escola. No que se refere ao perfil dos entrevistados, a pesquisadora mostra que a maioria dos jovens em LA: são adolescentes do sexo masculino, cujos pais em sua maioria não possuem escolaridade; a maioria reside em casa alugada; muitos não souberam identificar sua etnia e se consideraram pardos; a maioria mora com a mãe; a renda bruta da casa não chega a 1 salário mínimo; a maioria não possui internet em casa e muitos não conseguiram visualizar 0 que fariam nos próximos cinco anos. Ao serem indagados sobre o que pensam sobre 0 direito à educação, os depoimentos denotam que a educação está associada ao crescimento pessoal e econômico.

Ainda nesse contexto, Andrade (2016, p. 18) reflete: 


\section{OS DESAFIOS NA ESCOLARIZAÇÃO DE ADOLESCENTES EM CUMPRIMENTO DE MEDIDA SOCIOEDUCATIVA DE LIBERDADE ASSISTIDA}

Entre os dados levantados, a autora se aproxima da constatação de que os(as) adolescentes participantes de sua pesquisa, apesar de terem ingressado na escola com sete anos de idade, são "caracterizados[as]" por baixa escolaridade, evasão escolar, repetência e expulsões.

Considerando o exposto, os estudos de Castro (2016), Siqueira (2016) e Caparrós (2013) expõem as contradições das Orientações Pedagógicas do SINASE, uma vez que esse documento pontua que o "Brasil tem vencido o desafio da universalização da escolarização de sua população infanto - juvenil, garantindo vagas para todos, restando o desafio de melhorar a qualidade do ensino" (BRASIL, 2015, p. 37). Essas pesquisas mostram que, apesar da expectativa das políticas educacionais em relação à ampla inserção de adolescentes na escola, no cenário socioeducativo a realidade expressa a ausência de escola e de opções para encaminhamento dos jovens contemplando todas as séries.

Os dados das teses e dissertações expõem que a universalização do ensino ainda é uma realidade distante dos adolescentes brasileiros que cumprem medidas socioeducativas de Liberdade Assistida (AVILA, 2013; ANDRADE, 2016; CASTRO; 2016; SIQUEIRA, 2016, SOARES, 2017).

Fica, então, subentendido (ou mesmo explícito), o dever da escola de criar mecanismos para que todos os socioeducandos aprendam durante o período em que estiverem em cumprimento de medida socioeducativa. Entretanto, questiona-se que a educação vem atendendo somente as metas estatísticas que no fim não correspondem às reais demandas de inclusão dos jovens e acabam por não incidir na reelaboração das políticas educacionais mais atraentes e voltadas à realidade desses adolescentes (PAVEZI, 2013).

Nesse contexto, emerge o questionamento: Quando inseridos na escola, o que leva os adolescentes em LA a não permanecerem na instituição? Rocha (2014) atribui, primeiramente, ao contexto global, onde os fatores de ordem econômica, social e cultural interferem na permanência do aluno na escola. Por outro lado, entende essa não permanência ao refletir que a escola vem resistindo à modernização dos conteúdos, somado ao ensino tradicional, assim como à falta de estrutura e ausência de políticas de capacitação voltadas a professores.

Segundo Ávila (2013), a permanência dos adolescentes autores de atos infracionais na escola é também um desafio. No caso daqueles que cumprem medida socioeducativa de Liberdade Assistida, a não permanência na escola implica o descumprimento da medida.

A compreensão acerca das questões decorrentes da entrada e permanência do adolescente em cumprimento de medidas socioeducativas na escola implica em considerar que a educação escolar é atravessada e constituída por processos históricos, políticos, econômicos, sociais, culturais, éticos e, psicológicos. No ambiente escolar, identificam-se todas as tensões, conflitos, antagonismos que estão presentes na convivência coletiva (ÁVILA, 2013, p. 42). 
Com vistas a entender essa realidade, Piazzarollo (2015) identificou os fatores de risco para evasão escolar dos jovens no contexto de cumprimento da medida socioeducativa de Liberdade Assistida. A autora elencou os fatores de proteção relacionados à permanência destes, na escola: a rede de apoio familiar, o predomínio de pais com pelo menos o ensino médio, a boa frequência escolar na educação infantil, o bom relacionamento com a comunidade escolar, a participação em ações escolares que fomentem a motivação para estudar, a percepção pessoal do jovem quanto aos benefícios da permanência na escola, o hábito de estudar, o próprio cumprimento da medida socioeducativa de meio aberto em condições adequadas.

\begin{abstract}
A análise dos fatores de proteção associados à permanência na escola revela que elementos importantes na motivação em continuar estudando extrapolam a sala de aula e a relação de ensino-aprendizagem, compreendendo outras dimensões da vida escolar, como os bons relacionamentos, as visitas orientadas e as aulas de campo. Além disso, esse exame também aponta a relevância da rede de apoio do adolescente para sua vida escolar e geral e que, nesse suporte, mostraram-se fundamentais a atuação do pai, da mãe, dos alunos e dos professores. (PIAZAROLLO, 2015, p. 211).
\end{abstract}

O estudo supracitado ainda aponta os fatores de risco ${ }^{7}$ para a permanência dos adolescentes em cumprimento de Liberdade Assistida na escola, sendo os principais elencados: a pobreza, a necessidade de geração de renda imediata por meio do trabalho ou da prática de atos infracionais, pais com baixa escolaridade, uso de drogas, ausência de algum progenitor, envolvimento com situações ilegais e grupos que infringem as normas sociais, negligência por parte dos genitores, 0 abuso físico, as dificuldades com os relacionamentos interpessoais na escola, desânimo, falta de interesse ou vontade de voltar a estudar, a falta de investimento do governo na escola, pouca divulgação de serviços públicos como $0 E \mathrm{JA}^{8}$ e 0 Encceja ${ }^{9}$ especialmente para 0 retorno à escola (PIAZZAROLLO, 2015).

Collado (2013) atribui entre os motivos para a não permanência do adolescente autor de ato infracional na escola: a resistência do aluno, a diferença geracional no cotidiano escolar, a baixa escolaridade que não permite acompanhar os conteúdos formativos, a invisibilidade, a preferência do aluno por cursos de profissionalização, e, o principal: o aluno evadido não considera a escola significante.

Outro ponto que implica o caráter intermitente da participação do adolescente nas instituições de ensino é a indisciplina, retratada nos estudos de Collado (2013), Rocha (2014) e Costa (2013). A indisciplina escolar vem sendo resolvida pela escola a partir da adoção de medidas disciplinares, sem considerar que tais práticas podem resultar em abandono e processos excludentes e discriminatórios, revelando-se, assim, uma das faces da violência simbólica e institucional nesse ambiente. 


\section{OS DESAFIOS NA ESCOLARIZAÇÃO DE ADOLESCENTES EM CUMPRIMENTO DE MEDIDA SOCIOEDUCATIVA DE LIBERDADE ASSISTIDA}

A pobreza enquanto uma expressão da questão social, também se manifesta no âmbito da escola, constituindo-se como outra forma de manifestação da violência: a violência estrutural. Tal violência reflete obstáculos frente 0 acesso aos direitos, e, neste caso, o direito à educação, ao acesso e permanência na escola. A pobreza apresenta-se, assim, como um processo que acaba por reforçar a questão da evasão e abandono escolar, aprofundando a vulnerabilidade social dos jovens que vivenciam tal realidade e têm seus direitos fundamentais reiteradamente violados (ÁVILA, 2013).

Para Collado (2013), não somente o acesso, mas também a permanência na escola, devem ser considerados como dimensões de efetivação do direito à educação na LA. Dessa forma, o estudo aponta inconsistências no acompanhamento escolar dos jovens em Liberdade Assistida. Identificou-se ainda, que os operadores das políticas públicas acabam por utilizar inúmeros artifícios para induzir ao retorno escolar, envolvendo notificações, ameaças de cortes do bolsa família, suspensão de benefícios, persuasão dos pais, mas a maioria dos jovens não retorna aos estabelecimentos de ensino.

Torna-se, então, necessário, que muito se trabalhe para concretizar princípios já consagrados na legislação, como a garantia da absoluta prioridade a todas as crianças e adolescentes, inclusive os que estão em cumprimento de medidas, pois seus direitos estão previstos pela Constituição Federal e não podem ser menosprezados ou mal interpretados: adolescentes precisam ser compreendidos, respeitados e ter seus direitos garantidos.

No cenário socioeducativo é necessário pensar no papel político da socioeducação e sua relação com a economia na construção de políticas educacionais, passando pela dimensão da formação dos profissionais da educação e por um modelo educacional que promova o rompimento dos ciclos de violência vivenciados pelos adolescentes em LA.

\section{CONSIDERAÇÕES FINAIS}

A referida pesquisa teve enquanto objetivo abordar os desafios na escolarização dos adolescentes em Liberdade Assistida. Constata-se, através da problematização do tema que, sem dúvidas, a implementação da perspectiva pedagógica no ECA corresponde a uma nova forma de conceber crianças e adolescentes enquanto sujeitos em condição particular de desenvolvimento.

Através deste estudo foi verificada a presença de pedagogias conservadoras ao longo da implementação das políticas públicas voltadas às crianças e adolescentes. Nesse contexto, a educação emerge enquanto caminho para orientação dos adolescentes, mas, também, diretamente ligada às demandas dos processos produtivos relacionadas à intensa industrialização do país e demandas na economia. 
Frente à aplicação das medidas educacionais com finalidade de dirigir a conduta dos adolescentes que cometeram infrações, as escolas emergem enquanto espaços voltados à vigilância do público infanto-juvenil. Nesse contexto, a Liberdade Assistida, que no período Menorista existia sob a nomenclatura Liberdade Vigiada, já preconizava o encaminhamento desse segmento às chamadas Escolas de Reforma. Ainda na vigência da Doutrina de Situação Irregular a escolas aparecem como espaços onde os adolescentes eram disciplinados por equipes multiprofissionais que associavam a conduta transgressora às patologias.

A partir da vigência do ECA a socioeducação adquire outros delineamentos, cujas ações devem estar voltadas à Proteção Integral. No que se refere à Liberdade Assistida, verificam-se inúmeras dificuldades no que concerne à efetivação dos direitos dos adolescentes autores de infração, sendo uma das principais o não acesso à escolarização formal com garantia a qualquer tempo de matrícula.

A frequência escolar é um dos requisitos para o cumprimento da $L A$, todavia, se 0 adolescente não tem acesso à educação poderíamos falar em Liberdade Desassistida. Assim, as pesquisas mostram que a aplicabilidade atual da LA está mais comprometida com a punição e controle sociopenal dos adolescentes do que com o desenvolvimento integral desses jovens.

A educação e a socioeducação são as principais políticas voltadas ao acompanhamento dos adolescentes que cometem violência. Todavia, as pesquisas mostram que não vêm sendo desenvolvidas tecnologias sociais que permitam o desenvolvimento do que preconizam as diretrizes do SINASE. É como se o ideal socioeducativo permanecesse no campo das ideias e não estivesse sendo colocado em prática.

Esta pesquisa denota a necessidade de exploração teórica desse tema, sobretudo porque existem poucas produções cientificas que efetivamente problematizem a socioeducação no contexto da LA, sendo a maioria dos estudos voltados aos perfis dos adolescentes acompanhados e a operacionalização da referida medida.

\section{REFERÊNCIAS}

ADORNO, S; BORDINI, E. B. T.; LIMA, R. S. O adolescente e as mudanças na criminalidade urbana. São Paulo em Perspectiva. São Paulo, v. 13, n. 4, pp. 62-74, 1999. Disponível em: http://www.scielo.br/pdf/spp/v13n4/v13n4a06.pdf. Acesso em 6 jul. de 2019.

ANDRADE, P. A escola como direito e punição: o(a) adolescente em liberdade assistida. 2016. 131f. Dissertação (Mestrado em Educação) - Faculdade de Filosofia, Letras e Ciências Humanas, Universidade Federal de São Paulo. Guarulhos, 2016. 
ÁVILA, L. As medidas socioeducativas em meio aberto e a relação com a judicialização das violências nas escolas na cidade de Porto Alegre. 2013. 149f. Dissertação (Mestrado em Serviço Social) - Faculdade de Serviço Social- Pontifícia Universidade Católica do Rio Grande do Sul. Porto Alegre, 2013.

BRASIL. Constituição Federal de 1988. Promulgada em 5 de outubro de 1988.

BRASIL. Decreto n 17.943-A de 12 de outubro de 1927. Consolida as leis de assistência e proteção a menores, Coleção de Leis do Brasil. Rio de Janeiro, 31 dez. 1927.

BRASIL. Lei $n^{\circ} 8.089$, de 13 de julho de 1990. Dispõe sobre o Estatuto da Criança e do Adolescente e dá outras providências, Diário Oficial da União: República Federativa do Brasil. Brasília, 13 de jul. de 1990.

BRASIL. Lei n 6.697, de 10 de outubro de 1979. Institui o Código de Menores, Diário Oficial da União: República Federativa do Brasil. Brasília, 10 de out de 1979.

CAPARRÓS, R. Entre saberes, sabores e desafios da tarefa educativa com jovens em conflito com a lei: como as educadoras significam os processos educativos do espaço do programa de medidas socioeducativas em meio aberto. 2013. 174f. Dissertação (Mestrado em Educação) - Centro de Educação e Ciências Humanas- Universidade Federal de São Paulo. 2013.

CARVALHO, J. Cidadania no Brasil: o longo caminho. Rio de Janeiro: Civilização Brasileira, 2002.

CASTRO, D. A escola e o adolescente em Liberdade Assistida. 2016. 196f. Tese (Doutorado em Educação) - Escola de Formação de Professores e Humanidades- Pontifícia Universidade Católica de Goiás. Goiânia, 2016.

COLLADO, D. 0 direito à educação escolar do adolescente autor de ato infracional no município de Belo Horizonte. 2013. 145f. Dissertação (Mestrado em Educação) - Faculdade de Educação Universidade Federal de Minas Gerais. Belo Horizonte, 2013.

FALEIROS, V. Políticas para infância e adolescência e desenvolvimento. Revista Políticas Sociais: Acompanhamento e Análise, n. 11, pp. 171-177, 2005.

LOURENÇÃO, E. Processos de escolarização de adolescentes autores de ato infracional no município de Presidente Prudente. Dissertação (Mestrado em Educação) - Faculdade de Ciências e Tecnologia -Universidade Estadual Paulista. Presidente Prudente, p. 143. 2015.

MARINHO, F; GALINKIN, A. A história das práticas diante do desvio social de jovens no Brasil: reflexões sobre o ideal de ressocialização. Pesqui. prát. psicossociais, São João del-Rei, v. 12, n. 2, p. 280-297, 2017.

MDS. Secretaria Nacional de Assistência Social. Censo SUAS 2017: Resultados Nacionais. Brasília: Coordenação- Geral de Planejamento e Vigilância Socioassistencial, 2018.

ORTEGAL, L. A medida socioeducativa de Liberdade Assistida: fundamentos e contexto atual. 2011. 145f. Dissertação (Mestrado em Serviço Social) - Departamento de Serviço Social- Universidade de Brasília. Brasília, 2011. 
PAULA, L. Liberdade Assistida: punição e cidadania na cidade de São Paulo. 2011. 275f. Tese (Doutorado em Sociologia) - Faculdade de Filosofia, Letras e Ciências Humanas, Universidade de São Paulo. São Paulo, 2011.

PAVEZI, C. TÁ EM CASA! E agora? Noções dos ex-internos da Fundação CASA sobre escola e família. Dissertação (Mestrado em Educação). Universidade Nove de Julho. São Paulo, p. 146. 2013.

PEREZ, J; PASSONE, E. Políticas sociais de atendimento às crianças e aos adolescentes no Brasil. Cadernos de Pesquisa, v.10, n. 140, pp. 649-673, 2010.

PIAZZAROLLO, D. Fatores de risco e de proteção presentes na vida de adolescentes cumprindo liberdade assistida: Permanência e evasão escolar. 2015. 267f. Dissertação (Mestrado em Psicologia) - Centro de Ciências Humanas e Naturais- Universidade Federal do Espírito Santo. Espírito Santo, 2015.

REHDER, R. A medida socioeducativa de Liberdade Assistida como instrumento de cidadania. 2017. 96f. Dissertação (Mestrado em Direito) -Faculdade de Ciências Humanas e Sociais, Universidade Estadual Paulista. Franca, 2017.

RIZZINI, I; RIZZINI, I. A institucionalização de crianças no Brasil: Percurso histórico e presente. São Paulo: Loyola, 2004.

ROCHA, M. Conflito, diálogo e permanência: O professor mediador, o adolescente que cometeu ato infracional e a escola. 2014. 143f. Dissertação (Mestrado em Terapia Ocupacional). Centro de Ciências Biológicas e da Saúde. Universidade Federal de São Carlos. São Carlos, 2014.

SILVA, M. 0 controle sociopenal dos adolescentes com processos judiciais em São Paulo: entre a proteção e a punição. 2005. 267f. Tese (Doutorado em Serviço Social) - Faculdade de Serviço Social, Pontifícia Universidade Católica de São Paulo, São Paulo, 2005.

SILVA, M. Violência e controle sócio penal contra adolescentes com práticas infracionais. Revista Serviço Social \& Saúde, Campinas, v.9, n. 9, 2010.

SIQUEIRA, L. Adolescentes em "liberdade assistida": narrativas de (re)encontros com a escola. 2016. 190f. Tese (Doutorado em Educação) - Centro de Educação- Universidade Federal do Espírito Santo. Vitória, 2016.

SOARES, E. A avalição em contexto socioeducativo: perspectivas e desafios na escolarização de jovens em conflito com a lei. 2017. 402f. Tese (Doutorado em Educação) - Departamento em Educação - Universidade de Brasília, 2017.

ZANELA, M; LARA, A. O Código de Menores de 1927, o direito penal do menor e os congressos internacionais. Revista Angelus Novus. v. 1, n. 19, pp. 105-128, 2015.

Notas

\footnotetext{
${ }^{1}$ A Liberdade Assistida pressupõe certa restrição de direitos e um acompanhamento sistemático do adolescente, mas sem impor ao mesmo o afastamento de seu convívio familiar e comunitário. Essa medida é fixada pelo prazo mínimo de seis meses, podendo ser prorrogada, revogada ou substituída caso a Justiça determine (BRASIL, 1990).
} 


\section{OS DESAFIOS NA ESCOLARIZAÇÃO DE ADOLESCENTES EM CUMPRIMENTO DE MEDIDA SOCIOEDUCATIVA DE LIBERDADE ASSISTIDA}

2 Terminologia utilizada no Código de Menores de Melo de Mattos utilizada para nomear crianças e adolescentes em situação de abandono e delinquência. Nota-se que essas nomenclaturas possuem caráter estigmatizante e reducionista.

3 Terminologia utilizada no Código de Menores, referindo-se aos adolescentes que transgridem as normas sociais.

4 Terminologia empregada nos Códigos Menoristas, referindo-se às crianças e adolescentes.

5 A Escola Correcional Quinze de novembro, também denominada Premonitória Quinze de Novembro ou Quinze de Novembro, foi criada pelo decreto n. 4.780, de 2 de março de 1903, com a finalidade de dar educação física, profissional e moral aos menores abandonados e recolhidos ao estabelecimento por ordem das autoridades competentes.

6 O direito à educação é apresentado nas diretrizes do SINASE como um dos eixos estratégicos que paramentam a ação socioeducativa. Segundo o documento, deve ser garantido ao adolescente inserido no atendimento socioeducativo 0 acesso a todos os níveis de educação formal de acordo suas necessidades específicas, propiciando as condições adequadas à assimilação e produção de conhecimento (BRASIL, 2006a).

7 A pesquisa buscou investigar fatores de risco e de proteção presentes na vida de adolescentes cumprindo liberdade assistida para compreender os processos de permanência e evasão escolar, por meio de dois estudos realizados com adolescentes atendidos por instituições da Grande Vitória (ES) que executam essa medida (PIAZZAROLLO, 2015).

8 A Agenda Territorial de Desenvolvimento Integrado de Alfabetização e Educação de Jovens e Adultos tem o objetivo de firmar um pacto social, para melhorar e fortalecer a educação de jovens e adultos (EJA) no Brasil.

9 O Encceja tem como principal objetivo construir uma referência nacional de educação para jovens e adultos por meio da avaliação de competências. 